\title{
Investigation of the Effects of Zebularine on Caspase- 3 and Caspase-9 Involved in Anticancer and Apoptotic Mechanisms in SKBR3 Breast Cancer Cell Line
}

\author{
Onur Eroglu ${ }^{1,2^{*}}$, Merve Celen ${ }^{3}$ \\ ${ }^{1}$ Department of Molecular Biology and Genetics, Faculty of Science and Letters, Bilecik Seyh Edebali University, Bilecik, Turkey \\ ${ }^{2}$ Biotechnology Research and Application Center, Bilecik Seyh Edebali University, Bilecik, Turkey \\ ${ }^{3}$ Vocational School of Medical Services, Program of Medical Laboratory Techniques, Bilecik Seyh Edebali University, Bilecik, \\ Turkey \\ Email: *onur.eroglu@bilecik.edu.tr
}

How to cite this paper: Eroglu, O. and Celen, M. (2019) Investigation of the Effects of Zebularine on Caspase-3 and Caspase-9 Involved in Anticancer and Apoptotic Mechanisms in SKBR3 Breast Cancer Cell Line. Journal of Cancer Therapy, 10, 229-244.

https://doi.org/10.4236/jct.2019.103019

Received: February 15, 2019

Accepted: March 9, 2019

Published: March 12, 2019

Copyright (c) 2019 by author(s) and Scientific Research Publishing Inc. This work is licensed under the Creative Commons Attribution International License (CC BY 4.0).

http://creativecommons.org/licenses/by/4.0/

\begin{abstract}
The aim of this study is to investigate the anti-proliferative effects of Zebularine on caspase- 3 and 9 genes by methylation and protein expression on SKBR3 cells. The SKBR3 cells were treated with Zebularine at different concentrations $(0-140 \mu \mathrm{M})$ for $24-96$ hours and the effects on the cell viability were shown. The effects on the cell migration and cell transformation were also demonstrated at the specified dose $\left(\mathrm{IC}_{50}=40 \mu \mathrm{M}\right)$. At the same time, the HRM method and western-blot analysis were used to understand the effects in the apoptotic mechanism. According to the obtained results, it was observed that Zebularine significantly decreased the cell proliferation, cell migration and the cell growth $(\mathrm{p}<0.001)$. As a result of the methylation analyzes performed on SKBR-3 cells at the applied dose, it was observed that Zebularine caused a decrease in both caspase- 3 and 9 methylation rates at the $72^{\text {nd }}$ hour. However, both reductions in the methylation levels didn't cause a significant change ( $p>0.05)$. At the same time, it was detected by the western-blot analyses that there was a time dependent increase in caspase- 3 genes while a decrease was detected in the caspase- 9 gene in progress of time. The obtained results showed that the methylation changes occurring in the caspase genes weren't related to the protein levels. According to these results, supportive results are obtained showing that the Zebularine can be used in chemotherapy and that this study is unique since it is the first study in the literature intending to investigate the effects of Zebularine on the SKBR3 cells.
\end{abstract}




\section{Keywords}

SKBR3, Zebularine, Apoptosis, Breast Cancer

\section{Introduction}

Breast cancer is the most commonly observed type of cancer in women and the second most commonly cause of death by cancer [1]. However, it is rarely diagnosed in men and the men's breast cancer cases constitute less than $1 \%$ of all breast cancer cases [2]. Approximately 14.1 million patients were diagnosed with cancer worldwide and 8.2 million people died of cancer. The global cancer burden is expected to grow rapidly due to the aging population [3]. The majority of the breast cancer patients can be treated by hormone therapy, chemotherapy, surgical operation or radiotherapy. However, the treatments are not completely effective [4]. Therefore, it is important to develop new therapeutic agents.

Apoptosis is a defense mechanism that prevents the cells from forming tumors; moreover, it has a great importance in tumor regression in the response to chemotherapy [5]. However, in some cases many cancer cells escape from apoptosis and the formation of the tumor cannot be stopped [6]. One of the reasons for this is the deterioration of the regulation of caspase activation regulated by the proteolytic activity. Without any active caspase the cells do not undergo caspase-dependent cell death; however, survival may occur and even clonogenic tumor growth may occur [7].

The regulation of apoptosis is controlled by the caspases divided into two including initiator caspases (caspases 2 8, 9 and 10) and effector caspases (caspases 3,6 and 7) [8]. Effector caspases are produced as dimers in the cell and they are required to demonstrate efficiency in the proteolytic processing by an initiating enzyme. As a result, they target a broad spectrum of cellular proteins that lead to cell death. In contrast to the effector caspases, the initiator caspases are translated as monomeric zymogen. The formation of the multicomponent complexes induces the dimerization which is necessary for the activation of the initiating caspases [9] [10]. The effector caspases are involved in the decomposition of many cellular proteins and are responsible for the morphological changes in the apoptosis [11].

Caspase- 3 which is the focus point of our study is the most studied among the effector caspases. It plays an important role both in the extrinsic pathway initiated by caspase- 8 and in the intrinsic pathway involving caspase-9 [12] [13]. Abnormal caspase expression can be also observed in various cancers. Comparing to normal tissues, the expression of caspase- 3 was found to be higher in patients with acute myeloid leukemia [14] [15]. Contrary to this, the expression of caspase- 3 was found to be decreased in prostate tumors and in the MCF-7 cells of the breast cancer cell line [16] [17] [18]. At the same time, loss of caspase-8 mRNA/protein expression was detected in lung cancer and neuroblastomas [19] 
[20]. Additionally, loss of caspase-9 expressions occurred in neuroblastomas and testicular tumors [20] [21].

Based on these results, it was intended to investigate the effects of a new DNA methylation inhibitor and a cytidine analog called Zebularine on apoptotic mechanism [22]. The difference between Zebularine and the other DNA methyl transferase inhibitors (DNMTi) is the fact that Zebularine is stable and has low toxicity both in vivo and in vitro [23]. At the same time, it plays a role in the induction of apoptosis and it is a chemical agent with anti-tumor potential in the cancer cells [24] [25]. In this study, it is aimed to investigate the anti-proliferative effects of Zebularine on the SKBR3 cells of the breast cancer cell line, the methylation status of the caspase- 3 and 9 genes which are responsible on the apoptotic pathway and the effects of caspase- 3 on the protein levels. Our study has a great importance since there are not many studies available in the literature in this regard.

\section{Material and Methods}

\subsection{Cell Culture and Zebularine Treatment}

The SKBR-3 which is a breast cancer cell line was obtained from Prof. Dr. Oğuz Öztürk who is working for the Research Institute for Experimental Medicine. The SKBR-3 cells were produced within an incubator (New Brunswick-Galaxy $170 \mathrm{R}$ ) including $5 \% \mathrm{CO}_{2}$ at $37^{\circ} \mathrm{C}$ in DMEM (Lonza) medium containing $10 \%$ fetal bovine serum (FBS) (Biological Industries) and $1 \%$ penicillin/streptomycin (Biological Industries). The Zebularine was purchased from the Cayman chemicals and was dissolved in DMSO. In the proliferation experiments, the cells were treated with different concentrations of Zebularine $(0-140 \mu \mathrm{M})$. The cells were treated with $40 \mu \mathrm{M}$ of Zebularine during the Clonogenic Survival Assay, Wound Healing Assay, Colony Formation Assay, HRM and Western Blot Analysis and all the experiments were repeated 3 times.

\subsection{Cell Proliferation Assay}

The cell proliferation was performed by using MTT Assay. MTT reagent (Glentham Life Sciences) was added to the cells exposed to Zebularine. 4 hours later, DMSO (Merck Millipore) was added to obtain formazan crystals and then the results were monitored in a microplate reader (Thermo scientific-Multi scan Go) at 570 and $650 \mathrm{~nm}$.

\subsection{Viability Assay}

The principle of this experiment is based on the interaction between the cells with damaged membrane and the trypan blue. First of all, SKBR-3 cells were cultured in 6-well petri dishes in a way that there was $1 \times 10^{5}$ cell in each well and the cells were allowed to adhere to the surface. Zebularine $(40 \mu \mathrm{M})$ was applied to the cells at $\mathrm{IC}_{50}$ value determined at the end of the MTT test and the cells were incubated for different time periods. The treated cells were collected in 
tubes after being removed with the help of typsin-EDTA and centrifuged at 2000 rmp for $5 \mathrm{~min} .50 \mu \mathrm{M}$ medium and $50 \mu \mathrm{M}$ trypan dye were added to the pellet. The cells were loaded to hemocytometer and count was performed under inverted line microscope (Nicon Eclipse TS100).

\subsection{Wound Healing Assay}

The wound healing test was performed in order to examine the effects of Zebularine on cell migration and on the cell-cell interaction. SKBR-3 cells were cultured in 6-well petri dishes in a way that there was $25 \times 10^{4}$ cell in each well and the cells were allowed to adhere. The adherent cells were scraped in a straight line from the center of each well by the tip of a $200 \mu \mathrm{M}$ pipette. Wash was performed with $1 \times$ PBS in order to remove the cell remains. After washing $2 \mathrm{ml}$ of fresh both medicated (Zebularine $40 \mu \mathrm{M}$ ) and non-medicated (control group) media was added. The movements of the cells were monitored at the $24^{\text {th }}, 48^{\text {th }}$, $72^{\text {nd }}$ and $96^{\text {th }}$ hours and also their images were recorded.

\subsection{Anchorage-Independent Colony Formation Assay (Soft-Agar Assay)}

First of all, the 6-well petri dishes were plated with DMEM containing 20\% FBS and $0.6 \%$ agarose in 1:1 ratio and they were allowed to freeze. A mixture of DMEM (containing or not containing $40 \mu \mathrm{M}$ of Zebularine) including 10\% FBS and $0.3 \%$ agarose in $1: 1$ ratio were added to the top of the petri dishes in a way that it included $5 \times 10^{3}$ cell. They were allowed for incubation for 20 days. Every two days the upper medium was replaced with fresh medium. After 20 days the wells were treated with $0.005 \%$ crystal violet and were kept for 20 minutes. The colonies formed after the staining was examined under microscope.

\subsection{DNA Isolation and Bisulfide Modification}

Genomic DNA was isolated from the magnified SKBR-3 cells at the $24^{\text {th }}, 48^{\text {th }}$, and $72^{\text {nd }}$ hours after the application of Zebularine. At the same time, the isolation was also performed on the cells which were not treated with Zebularine for control purposes. The cells were lysed with prepared lysis buffer $(10 \mathrm{mM}$ Tris-HCI (pH 8), $0.1 \mathrm{M}$ EDTA ( $\mathrm{pH} \mathrm{8),0.5 \%} \mathrm{SDS)} \mathrm{and} \mathrm{the} \mathrm{DNA} \mathrm{isolation} \mathrm{was}$ carried out by the conventional phenol /chloroform method. The DNA amounts were measured by using BioSpec-nano (Shimadzu Corporation, Japan). The obtained DNA was subjected to bisulfite modification by using the EZ DNA Methylation Lightning Kit protocol (Zymo Research, Orange, CA) and after the modification the DNA samples were analyzed.

\subsection{MS-HRM Analysis}

The MS-HRM Analysis was carried out by using the AriaMx Real Time PCR System device (Agilent Technologies, Santa Clara, CA). The used primers were given in Table 1. Epitect PCR Control DNA Set (Qiagen) was used to evaluate 
Table 1. Primers used in MS-PCR analysis.

\begin{tabular}{ccc}
\hline Genes & & Primer Sequence \\
\hline \multirow{3}{*}{ Caspase-3 } & Unmetile Forward & 5'-TGAGTTTTAGGGTGGGATTAAAGT-3' \\
& Unmetile Revers & 5'-CACTACAACCCATCCCCTAA-3' \\
& Metile Forward & 5'-TTTAGGGCGGGATTAAAGC-3' \\
& Metile Revers & 5'-CTACGACCCGTCCCCTAA-3' \\
\hline \multirow{3}{*}{ Caspase-9 } & Unmetile Forward & 5'-GTGGGGAGTGAAGATTGATTT-3' \\
& Unmetile Revers & 5'-CCACTTCATCCATAACAAATAACC-3' \\
& Metile Forward & 5'-GGGAGC GAAGATTGATTC-3 \\
& Metile Revers & 5'-CTTCGTCCATAACGAATAACC-3 \\
\hline
\end{tabular}

the samples. The methylated and non-methylated DNAs were mixed in the ratio of $25 \%, 50 \%$, and $75 \%$ in order to form dilutions and the methylated/non-methylated standard DNAs were used in each assay. The reaction mixture $2 \times$ Brillant HRM Ultra FastLoci Master Mix (Agilent Technologies) was prepared from 10 ng bisulfite transformed DNA sample in a way that the final volume included 20 $\mu \mathrm{M}$. The reaction conditions were applied as given in Table 2. Each reaction was repeated twice. The melting curves were normalized by calculating the line of best fit between the two normalization zones before and after the large fluorescence reduction representing the melting of PCR products by using the AriaMx software and the comparison of the samples having different initial fluorescence levels was allowed through this algorithm.

\subsection{Western Blotting Analysis}

The protein samples were obtained from both the Zebularine-treated and not treated SKBR-3 cells. The samples were standardized by using the Bradford method. After the measurements, the proteins were mixed with laemmli solution (Bioland Scientific) in 1:1 ratio and were denatured for 5 minutes at $95^{\circ} \mathrm{C}$. The protein samples were loaded into $12 \%$ polyacrylamide gel and were conducted in $1 \times$ TAE solution at $90 \mathrm{~V}$ for 6 hours. The iBlot 2 Dry Blotting System (Thermo Fisher Scientific, US) was used for the transfer process and the transfer process was carried out according to the instruction of the device. After the transfer process, the membrane was blocked for an hour in the blocking solution (TBS-T (Tris-buffered saline, $0.1 \%$ Tween 20) (prepared with 5\% milk powder). After the blocking, the membranes were treated with primer antibodies (anti-GAPDH (1:1000), anti-casp-9 (1:1000) and anti-casp-3 (1:1000) for 24 hours at $4^{\circ} \mathrm{C}$. After the washing process, the membranes were treated with secondary antibodies (1:5000 dilution) for 24 hours at $4^{\circ} \mathrm{C}$. The membranes which were passed through ECL solution after a repeated washing procedure were visualized by using the G-box gel imaging system (Syngene, USA).

\subsection{Statistical Analysis}

All the analyses were carried out by using Microsoft Excel and SPSS (SPSS INC., Chicago, IL, USA) programs. The Two-tailed Student's T test and the One-way 
Table 2. Reaction conditions.

\begin{tabular}{cccc}
\hline Segment & Cycle & Temperature & Duration \\
\hline Hot Start & 1 & $95^{\circ} \mathrm{C}$ & 3 minutes \\
\hline \multirow{2}{*}{ Amplification } & 40 & $95^{\circ} \mathrm{C}$ & 5 seconds \\
& & $60^{\circ} \mathrm{C}$ & 20 seconds \\
\hline \multirow{2}{*}{ High Resolution Melt } & 1 & $95^{\circ} \mathrm{C}$ & 30 seconds \\
& & $65^{\circ} \mathrm{C}$ & 30 seconds \\
& $95^{\circ} \mathrm{C}$ & 30 seconds \\
\hline
\end{tabular}

ANOVA analyses were used according to the number of the variable. The statistical significance levels were determined as ${ }^{*} \mathrm{p}<0.05,{ }^{* *} \mathrm{p}<0.01$ and ${ }^{* *} \mathrm{p}<$ 0.001 .

\section{Results}

\subsection{The Effects of Zebularine on the Cell Proliferation}

In this study, SKBR3 breast cancer cell line with ER (-) and PR (-) phenotype was used. Although there are many studies conducted on SKBR3 and the chemotherapy agent, the effects of Zebularine have not been fully explained yet. MTT Assay and Survival Assay were applied in order to investigate the effects of Zebularine on the proliferation of SKBR3 cells. During the MTT Assay applications various doses of Zebularine $(0-140 \mu \mathrm{M})$ were applied to the cells for 24 hours. As a result, the SKBR3 cells were susceptible to Zebularine and a decreased was observed in the proliferation within the increased doses (Figure 1). At the end of the MTT assay, the $\mathrm{IC}_{50}$ value was determined as $40 \mu \mathrm{M}$. In order to investigate the time-related effects of Zebularine, Zebularine was applied to the cells at $\mathrm{IC}_{50}$ value and the cells were counted at the $24^{\text {th }}, 48^{\text {th }}, 72^{\text {nd }}$ and $96^{\text {th }}$ hours. According to the counts, a significant time-dependent decrease was detected in the cell proliferation compared to the control group (Figure 2).

\subsection{The Effects of Zebularine on Cell Migration and Growth}

Wound Healing Assay was carried out in order to examine in more detail how Zebularine affects the migration of the cells. While the wound was almost completely closed in the cells which were not treated with Zebularine, the wound healing was prevented in the cells to which Zebularine was applied (Figure 3(a) and Figure 3(b)). As a result of the examinations, migration was not observed in the cells even after 96 hours (Figure 3(a) and Figure 3(b)). According to these results, Zebularine helped to prevent the cell proliferation and cell mobility.

Anchorage-Independent Colony Formation Assay was performed in order to evaluate the effects of Zebularine on the independent growth of the cells on the surface. The SKBR3 cells were suspended in soft agar and they were allowed to grow for 20 days in the presence and absence of Zebularine. The obtained data showed that the colony diameter of the cells treated with Zebularine was smaller than the diameter of the untreated cells (Figure 4). This showed that the breast 


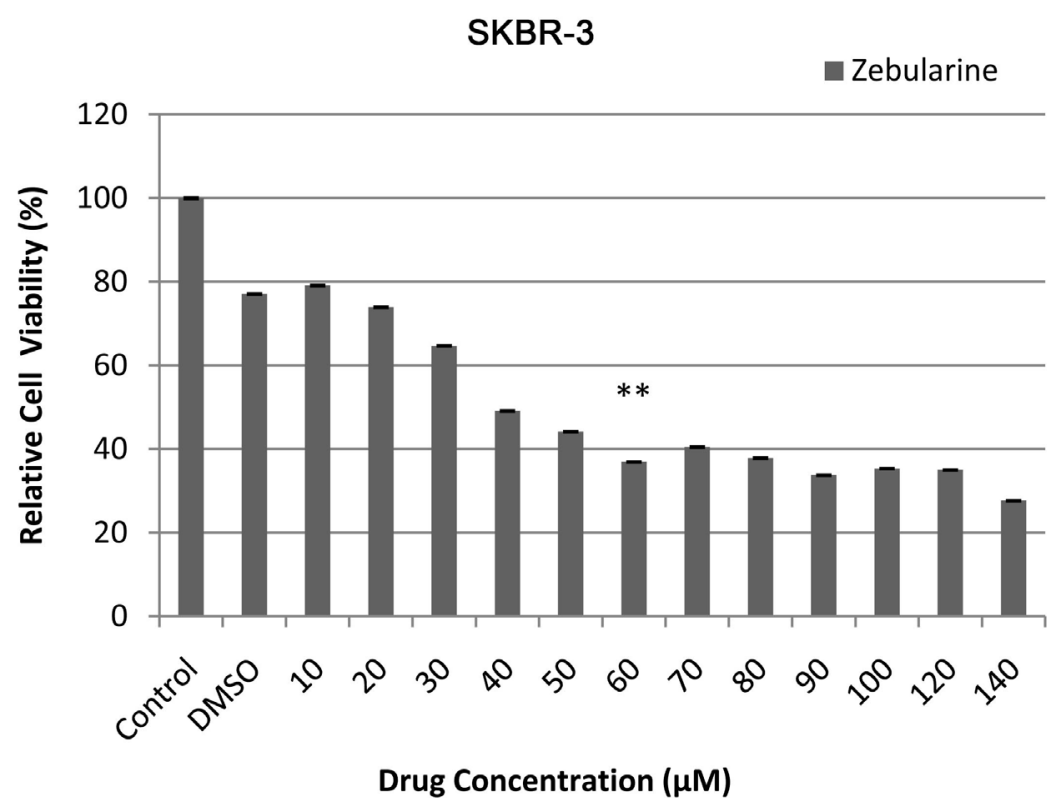

Figure 1. Growth curve inhibition as assessed by MTT assay in human breast cancer cell (SKBR3). SKBR3 cells were exposed to different doses of Zebularine for $24 \mathrm{~h}$ at $37^{\circ} \mathrm{C}$. The cell viability in breast cancer cells decreased in dose-dependent fashion. The IC-50 value for SKBR3 was observed to be $40 \mu \mathrm{M}$. Data are representative of three independent experiments done in triplicates and expressed as mean \pm S.E.M. ${ }^{* *} \mathrm{p}<0.01$ represents statistical significant difference between control and Zebularine test groups.

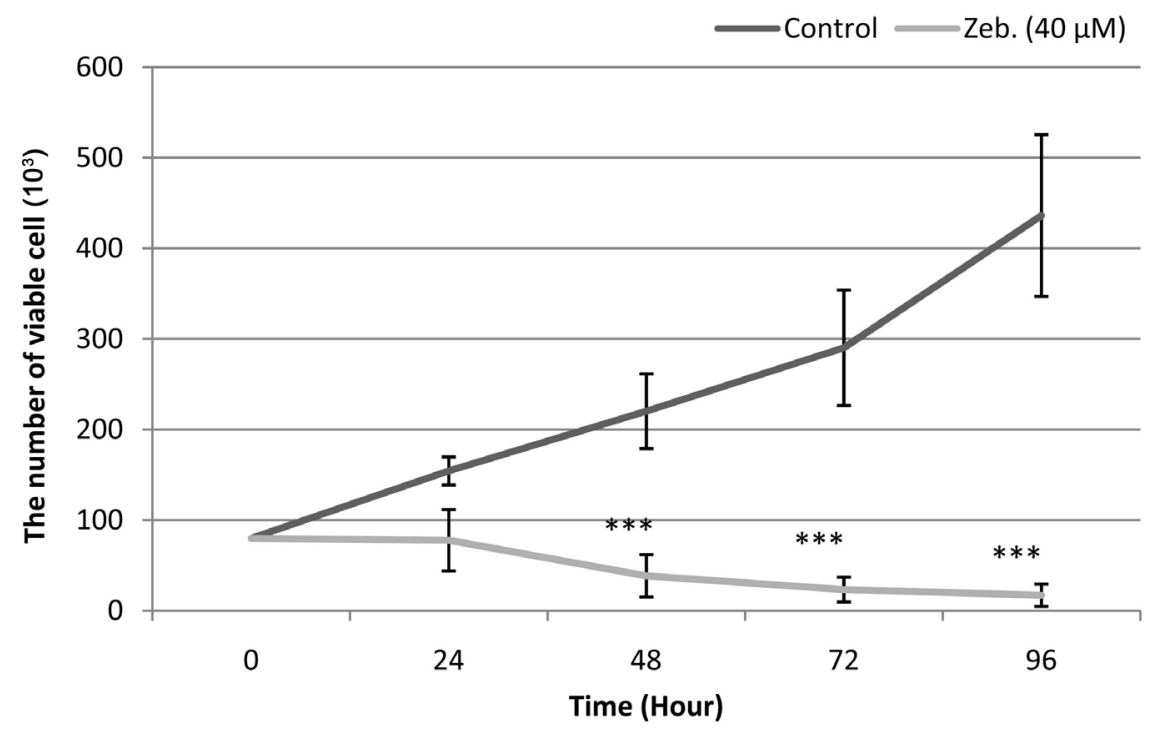

Figure 2. The effects of Zebularine $(40 \mu \mathrm{M})$ on time-dependent cell viability as assessed by Survival Assay in human breast cancer cell (SKBR3). SKBR3 cells were exposed $40 \mu \mathrm{M}$ $\left(\mathrm{IC}_{50}\right.$ value) dose of Zebularine for $24 \mathrm{~h}, 48 \mathrm{~h}, 72 \mathrm{~h}$ and $96 \mathrm{~h}$ at $37^{\circ} \mathrm{C}$. The cell viability in breast cancer cells decreased in dose-dependent fashion. Data are representative of three independent experiments done in triplicates and expressed as mean \pm S.E.M. ${ }^{* *} \mathrm{p}<0.001$ represents statistical significant difference between control and Zebularine test groups.

cancer cells that could grow independently for the surface were prevented from the growing by the Zebularine. 


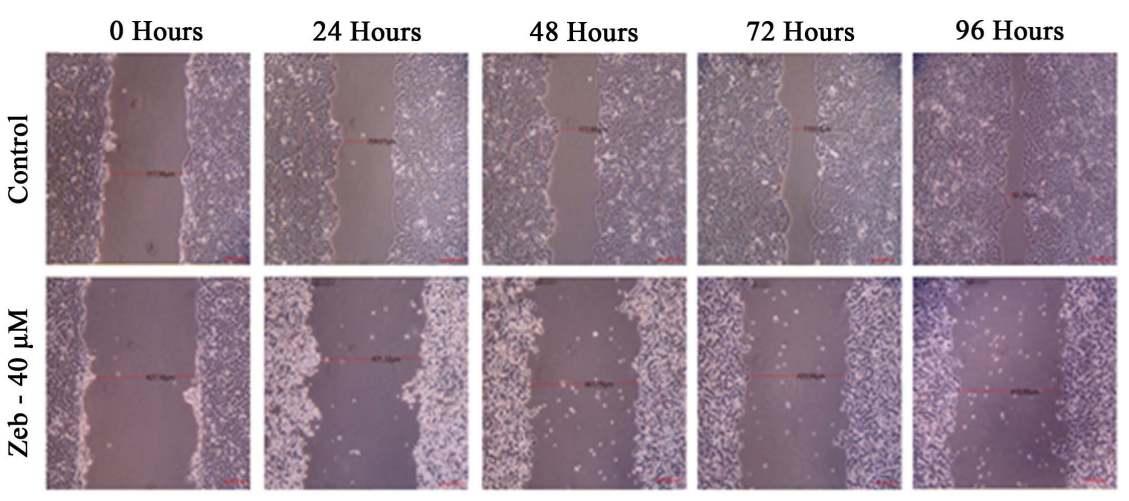

(a)

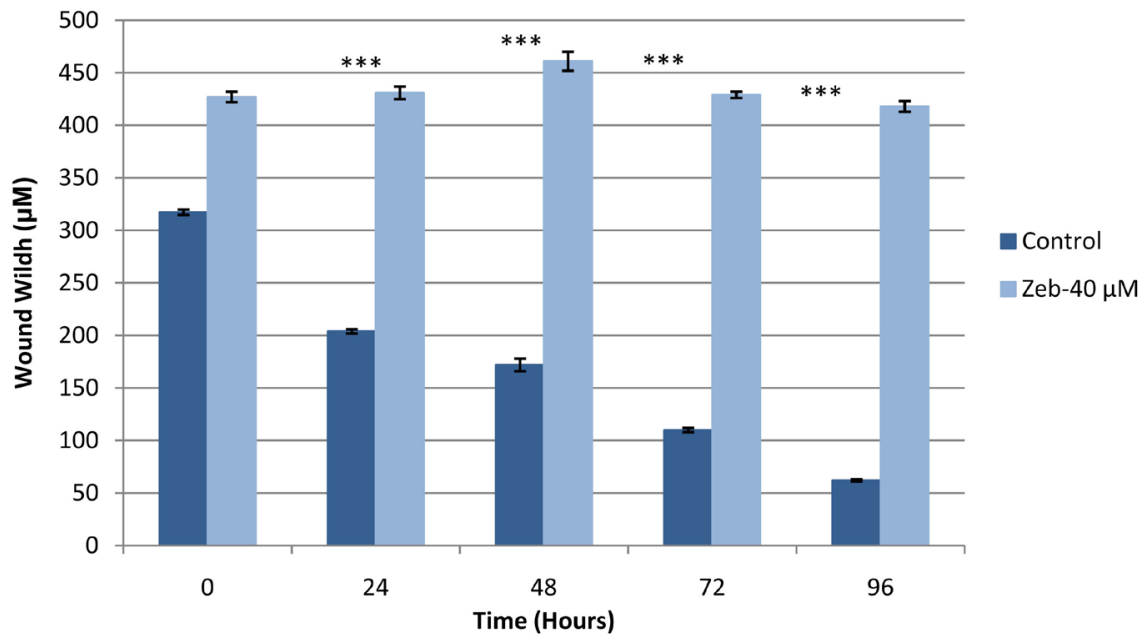

(b)

Figure 3. Wound healing assay for SKBR3 treated with Zebularine. Zebularine treatment reduced the wound healing capability of breast cancer cells. (a) Untreated and treated in SKBR3 cells $0 \mathrm{~h}, 24 \mathrm{~h}, 48 \mathrm{~h}, 72 \mathrm{~h}$ and $96 \mathrm{~h}$ after the wound induction. The distance between wounds was measured in three areas of cell cultures as means to quantify the cell migration (40x magnification); (b) The histograms are presented with the statistically significant difference $(\mathrm{p}<0.001)$.

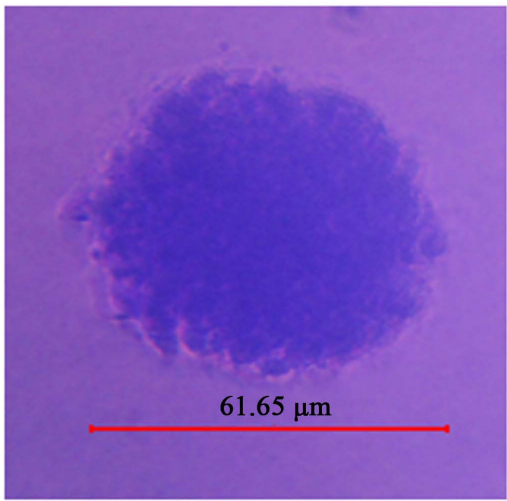

(a)

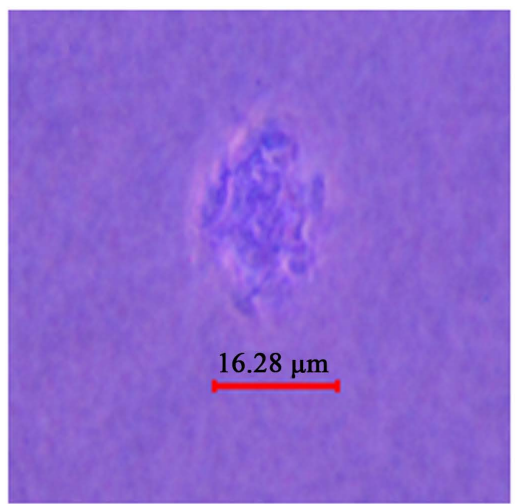

(b)

Figure 4. Anchorage-independent growth in the soft agar of SKBR3 cells with or without Zebularine. Upon treatment with Zebularine, these cells are smaller (right panel) and more colony (left panel) compared to untreated cells. 


\subsection{The Effects of Zebularine on the Caspase-3 and Caspase-9 Methylation Levels}

MS-HRM studies were carried out to evaluate the effects of Zebularine on the methylation changes in the SKBR3 breast cancer cell line. The MS-HRM analyzes were performed after the bisulfite medication process was carried out with the DNAs obtained from the cell culture.

MS-HRM used the melting profiles obtained from the DNA amplicons derived from bisulfite modified samples. The obtained melting curve provides a combination of the melting curves of the methylated and non-methylated samples. The PCR product obtained from the non-methylated sample had lower melting temperature compared to the PCR product obtained from the methylated sample. The PCR product obtained from the non-methylated sample starts to melt at a relatively lower temperature and then there is a significant decrease in fluorescence [26]. The products obtained from the methylated samples have higher melting temperature. As a result, the methylation conditions of the samples can be evaluated by comparing the samples with the known methylation conditions. For this purpose, in each reactions control DNAs with known methylation percentages ( $100 \% \mathrm{M}, 75 \% \mathrm{M}, 50 \% \mathrm{M}, 25 \% \mathrm{M}$, and $100 \% \mathrm{UM})$ were used and the methylation levels of the samples were determined by comparing with the control DNAs.

In this study, the methylation conditions of caspase 3 and 9 which were the important components of the apoptotic mechanism before and after the application of Zebularine, were analyzed. According to the obtained findings significant change was not found in the methylation levels of the caspases although the methylation levels of caspase- 3 and 9 was observed to be decreased at the $72^{\text {nd }}$ hour (Table 3) ( $\mathrm{p}>0.05)$.

\subsection{Effects of Zebularine on the Protein Levels of Caspase-3 and Caspase-9}

At the same time, the protein levels of the caspase- 3 and caspase- 9 involved in the apoptotic mechanism were evaluated through the western blot analysis conducted on the protein samples obtained from the SKBR-3 cells. There was a time-dependent increase at the inactive caspase-3 level after treating the SKBR-3 cells with Zebularine (Figure 5). At the same time, the caspase-9 levels were also

Table 3. Changes occurring in the methylation rates of the caspase- 3 and caspase- 9 genes obtained from the MS-HRM analysis.

\begin{tabular}{|c|c|c|c|c|c|c|}
\hline & \multirow{2}{*}{$\begin{array}{l}\text { Gene } \\
\text { Name }\end{array}$} & \multicolumn{5}{|c|}{ Methylation Rate } \\
\hline & & $0 \%-25 \%$ & $25 \%-35 \%$ & $35 \%-45 \%$ & $45 \%-55 \%$ & $55 \%-75 \% \quad 75 \%-100 \%$ \\
\hline \multirow{2}{*}{ Untreated } & Casp3 & & & & $\mathrm{X}$ & \\
\hline & Casp9 & & & & & $\mathrm{X}$ \\
\hline \multirow{2}{*}{ Treated } & Casp3 & & & $\mathrm{X}$ & & \\
\hline & Casp9 & & & & $\mathrm{X}$ & \\
\hline
\end{tabular}




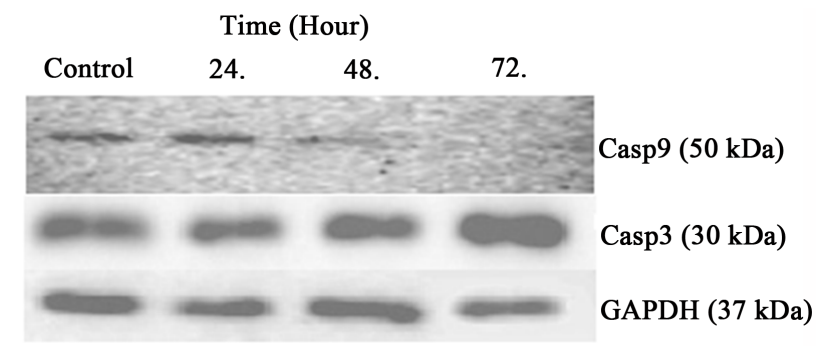

Figure 5. The results of western blot analyses of the apoptosis related proteins (caspase- 3 and caspase-9) in the SKBR-3 cells. Equal amounts of protein from untreated SKBR3 cells and drug applied SKBR3 cells (time-dependent) were loaded on a gel, separated, and transferred to a PVDF membrane and then probed with a monoclonal anti-caspase- 3 and anti-caspase- 9 antibody. Blotting with an antibody to GAPDH was used as a loading control. Similar results were observed in three independent experiments.

evaluated through the western blot analyses. The results showed that the levels of inactive caspase- 9 were decreased time-dependently in the SKBR- 3 cells treated with Zebularine (Figure 5).

\section{Discussion}

In cancer, covalent changes such as the addition of methyl group to genomic DNA more often occur compared to genetic changes [27]. These changes allow the muting of the genes and allow the cells to gain resistance in chemotherapy. One of the therapeutic agents used in recent years is Zebularine which is also effective in the mechanism of DNA methylation and there are several studies regarding this field [28] [29] [30]. However, the number of studies conducted on breast cancer in relation with Zebularine is not sufficient. Since there was no study available in the literature in this regard, this study was carried out to investigate the effects of Zebularine on the SKBR3 breast cancer cell line.

One of the reasons why Zebularine is chosen among the other DNMTi inhibitors is the fact that Zebularine can be effective at lower concentration as well. Moreover, this medication has low toxicity. In the conducted study, it was observed that Zebularine which was a DNA methyl transferase inhibitor had anti-tumor effects on SKBR3 breast cancer cell line. It was detected that the treatment of Zebularine induced the apoptosis mechanism in the SKBR cells and prevented the tumor formation. With the help of MS-HRM studies it was observed that changes occurred in the methylation status of the caspase genes that were effective on apoptosis mechanism.

Respectively, MTT assay, survival assay, anchored-dependent colony formation assay and wound healing assay were carried out in order to evaluate the effects of Zebularine on the cell death, growth and migration in the SKBR3 cells depending on time and dose. Previously conducted studies revealed that Zebularine had anti-tumor effects on cancers such as head and neck cancer, cholangiocarcinoma, colorectal cancer and leukemia [25] [30] [31] [32]. When considering the dose-dependent effects of Zebularine on the SKBR3 cells , the $\mathrm{IC}_{50}$ value was determined as $40 \mu \mathrm{M}$. Comparing to the values found previously in the 
MCF-7 breast cancer cell line and MDA-MB-231 cells, the concentration was found to be lower and this reduced the cytotoxic effect. When the time-dependent effects were considered, a significant decrease was observed in SKBR3 cells after 48 hours. In gastric cancer and ovarian cancer, the cell death was observed to be similar to our study, which also supported our research [33] [34].

On the other hand, the invasion of the cancer cells into the surrounding tissues is the first stage of the tumor metastasis and it requires the metastasis to adhere to the extracellular matrix and the chemotactic migration of the cancer cells which are directed by the protruding movement of the cell membrane [35]. When considering the effects of Zebularine on cell growth and migration, Hellebrekers et al. (2006) evaluated the effects of Zebularine on the cell migration in the human umbilical and endothelial cells (HUVEC) and detected significant changes [36]. It was found to be more effective compared to the other DNMTis. In another study conducted on lens epithelial cells, it was observed that the cell migration was suppressed again [37]. In this study, the effect of Zebularine on the cell migration in SKBR-3 breast cancer cell line was investigated with the help of the wound healing test. After the application the Zebularine $(40 \mu \mathrm{M})$ the cell migration was monitored from the $24^{\text {th }}$ hour to $96^{\text {th }}$ hour and as a result of the observation it was found that Zebularine prevented the cell migration significantly $(\mathrm{p}<0.001)$.

These results also showed that Zebularine prevented the cell metastasis by suppressing the cell migration and cell to cell interactions in the SKBR3 breast cancer cell.

In addition to this, with the help of the soft-agar colony formation test it was investigated whether the Zebularine grew independently from the surface. Through cell transformation the cells can undergo a malignant transformation to form a tumor. Due to this transformation, growth may happen independently from the surface. As a result of the research, it was found that the cell transformation of the SKBR-3 cells treated with Zebularine was largely suppressed and prevented from growing $(\mathrm{p}<0.001)$. Consequently, the tumor formation of the cells was prevented by a malignant transformation.

Another important feature of Zebularine is that unlike the other DNMT inhibitors it tends to prefer the cancerous cells rather than the normal fibroblasts. Therefore, compared to normal fibroblasts, it seemed to suppress the cell growth at the tumor cell line more. At the same time, it primarily blocks DNMT1 and can stimulate the cancer-associated antigen genes in cancer cells. Since it stimulates the cancer-associated antigen genes, when it was combined with immunotherapy, a group of cancer and apoptosis-associated genes were found which supported the possibility of the anti-tumor potential [29].

The apoptosis mechanism is one of the most important and effective mechanisms in the fight against cancer. It is regulated in two ways including intrinsic and extrinsic ways. There are many components which are involved in the activation and inhibition of apoptosis. Caspase is one of the most important components which are involved in stimulating apoptosis. They are studied in three 
groups including initiators, effectors and inflammatory caspases. Caspases are present in the cell as zymogen in inactive form. The initiator caspases cause dimer formation and becomes activated by passing through a series of cutting processes after being stimulated. The activated initiator caspases are effective in inducing the effector caspases. They allow the effector caspases to undergo the proteolytic cleavage and to become activated by stimulating them [38]. Caspase-9 which was included in our study was also one of the initiating caspases. It is effective in inducing apoptotic activation via intrinsic (mitochondrial) pathways. As one of the components of the apoptosis complex, it induces the stimulation of the mitochondrial cytochrome and this way it plays an important role in the activation of the effector caspases in response to various death stimuli. A number of post-transitional modifications occur in caspase-9. One of them is phosphorylation and many phosphorylation areas have been identified so far. This phosphorylation regulates the proteolytic cleavage of the caspase-9. Beside the phosphorylation, they are also effective in regulating nitrosylation and ubiquitination [39].

Caspase- 3 is one of the major caspases which is effective in apoptosis and also affected by caspase-9. The caspase- 3 is included within the class of effector caspases and it can be stimulated by both apoptotic pathways. Caspase- 3 is the best defined effector caspase. The conducted studies also revealed that it had distinct and overlapping roles with caspase- 7 and caspase- 6 . It is regulated by post-translational modifications just as in caspase-3 and caspase-9 [38]. Phosphorylation and ubiquitination are some of these modifications and have effects in the regulation of caspase-3. As a result of the caspase- 3 activation the apoptosis is stimulated. The caspases are available in zymogenous form and can become activated in a short time in the presence of appropriate stimuli. Therefore it is important to understand the mechanisms of regulations. Studies have been conducted on the caspase level is in relation with many diseases especially cancer. This study intended to investigate whether Zebularine had any effects on caspase methylation and on the protein levels in the SKBR-3 cells. Several studies have been conducted previously on this issue. The apoptotic activity of Zebuline was investigated in SCC-9 and SCC-25 head and neck cancer cell lines and a significant increase was observed in the levels of caspase-3 active form [25]. Another research showed that Zebularine induced the caspase-dependent apoptosis in Jurkat which was a P53 mutant, in CEM-6 and MOLT-4 leukemic T cells [31]. In a study conducted by Nakamura et al. (2013) on HepG2 and HeLa cells when the protein levels of caspase-3/7-8 and 9 was investigated, it was observed that the protein levels increased significantly [40]. According to the results obtained from the conducted study, a time-dependent increase was observed in the caspase-3 levels of the SKBR-3 cells after the application of Zebularine. However, over the time a decrease was detected in the caspase- 9 level. The results show that the increase in caspase- 3 level may be through the extrinsic pathway. However, the obtained data is not sufficient and the other components that are effective in the pathway should be also investigated for the better understanding. 
Epigenetic mechanisms are one of the mechanisms which are effective in the development of cancer. DNA methylation is the most studied one among them and many studied were carried out in the recent years to understand its effect in cancer. In a research conducted by Eroglu et al. (2018) on breast cancer tissues by using MS-HRM method, the levels of GSTP1 and CDH1 genes were investigated and this is one of the examples to be shown in this regard [41]. Due to the newly developed techniques, the methylation changes occurring in the genes can be easily identified. In this study, the effects of Zebularine were investigated on the methylation changes of the caspase- 3 and caspase- 9 genes which were responsible for the apoptosis mechanism on the SKBR3 breast cancer cell line by using the MS-HRM method in order to clarify this issue but no significant change was observed that might lead to any change in the methylation levels. The results say that the methylation changes do not have any effects in the activation or regulation of caspase-3 and caspase-9. However, more detailed studies are needed to make a clear comment.

Consequently, as a result of the conducted studies it has been shown for the first time in the literature that Zebularine suppressed significantly the cancer cell growth, cell migration and cell transformation in the SKBR-3 breast cancer cells. In addition, the effects of Zebularine on the methylation of caspases in SKBR3 cells have been investigated for the first time in the literature and it has been detected that Zebularine did not cause a significant change in the methylation of caspases at the applied doses and times. This shows that the caspase stimulation that is responsible for the apoptosis mechanism is not caused by methylation. According to these results, supportive results were obtained about the fact that Zebularine can be used in chemotherapy. This research is unique in the literature since it is the first study to investigate the effects of Zebularine on SKBR3 cells. However, in order to understand the effect mechanism of Zebularine better, the caspase-dependent apoptosis mechanism should be clarified in the future studies.

\section{Conflicts of Interest}

The authors declare no conflicts of interest.

\section{References}

[1] Jemal, A., Siegel, R., Xu, J. and Ward, E. (2010) Cancer Statistics, 2010. CA: $A$ Cancer Journal for Clinicians, 60, 277-300. https://doi.org/10.3322/caac.20073

[2] Curado, M.P., Edwards, B., Shin, H.R., Storm, H., Ferlay, J., Heanue, M. and Boyle, P. (2007) Cancer Incidence in Five Continents. IARC Press, International Agency for Research on Cancer, Lyon, Vol. 9.

[3] Ferlay, J., Soerjomataram, I., Dikshit, R., Eser, S., Mathers, C., Rebelo, M. and Bray, F. (2015) Cancer Incidence and Mortality Worldwide: Sources, Methods and Major Patterns in GLOBOCAN 2012. International Journal of Cancer, 136, E359-E386. https://doi.org/10.1002/ijc.29210

[4] Moongkarndi, P., Kosem, N., Kaslungka, S., Luanratana, O., Pongpan, N. and Neung- 
ton, N. (2004) Antiproliferation, Antioxidation and Induction of Apoptosis by Garcinia mangostana (Mangosteen) on SKBR3 Human Breast Cancer Cell Line. Journal of Ethnopharmacology, 90, 161-166. https://doi.org/10.1016/j.jep.2003.09.048

[5] Olsson, M. and Zhivotovsky, B. (2011) Caspases and Cancer. Cell Death and Differentiation, 18, 1441-1449. https://doi.org/10.1038/cdd.2011.30

[6] Kerr, J.F., Wyllie, A.H. and Currie, A.R. (1972) Apoptosis: A Basic Biological Phenomenon with Wideranging Implications in Tissue Kinetics. British Journal of Cancer, 26, 239-257. https://doi.org/10.1038/bjc.1972.33

[7] Fischer, U., Janssen, K. and Schulze-Osthoff, K. (2007) Does Caspase Inhibition Promote Clonogenic Tumor Growth? Cell Cycle, 6, 3048-3053.

https://doi.org/10.4161/cc.6.24.5118

[8] Lu, Y. and Chen, G.Q. (2011) Effector Caspases and Leukemia. International Journal of Cell Biology, 2011, Article ID: 738301. https://doi.org/10.1155/2011/738301

[9] Boatright, K.M., Renatus, M., Scott, F.L., Sperandio, S., Shin, H., Pedersen, I.M. and Salvesen, G.S. (2003) A Unified Model for Apical Caspase Activation. Molecular Cell, 11, 529-541. https://doi.org/10.1016/S1097-2765(03)00051-0

[10] Degterev, A., Boyce, M. and Yuan, J. (2003) A Decade of Caspases. Oncogene, 22, 8543-8567. https://doi.org/10.1038/sj.onc.1207107

[11] O’Donovan, N., Crown, J., Stunell, H., Hill, A.D., McDermott, E., O’Higgins, N. and Duffy, M.J. (2003) Caspase 3 in Breast Cancer. Clinical Cancer Research, 9, 738-742.

[12] Keane, M.M., Ettenberg, S.A., Nau, M.M., Russell, E.K. and Lipkowitz, S. (1999) Chemotherapy Augments TRAIL-Induced Apoptosis in Breast Cell Lines. Cancer Research, 59, 734-741.

[13] Bellarosa, D., Ciucci, A., Bullo, A., Nardelli, F., Manzini, S., Maggi, C.A. and Goso, C. (2001) Apoptotic Events in a Human Ovarian Cancer Cell Line Exposed to Anthracyclines. Journal of Pharmacology and Experimental Therapeutics, 296, 276 283.

[14] Estrov, Z., Thall, P.F., Talpaz, M., Estey, E.H., Kantarjian, H.M., Andreeff, M. and Kornblau, S.M. (1998) Caspase 2 and Caspase 3 Protein Levels as Predictors of Survival in Acute Myelogenous Leukemia. Blood, 92, 3090-3097.

[15] Pu, X., Storr, S.J., Zhang, Y., Rakha, E.A., Green, A.R., Ellis, I.O. and Martin, S.G. (2017) Caspase-3 and Caspase-8 Expression in Breast Cancer: Caspase-3 Is Associated with Survival. Apoptosis, 22, 357-368. https://doi.org/10.1007/s10495-016-1323-5

[16] Winter, R.N., Kramer, A., Borkowski, A. and Kyprianou, N. (2001) Loss of Caspase-1 and Caspase-3 Protein Expression in Human Prostate Cancer. Cancer Research, 61, 1227-1232.

[17] Blanc, C., Deveraux, Q.L., Krajewski, S., Jänicke, R.U., Porter, A.G., Reed, J.C. and Marti, A. (2000) Caspase-3 Is Essential for Procaspase-9 Processing and CisplatinInduced Apoptosis of MCF-7 Breast Cancer Cells. Cancer Research, 60, 4386-4390.

[18] Yang, X.H., Sladek, T.L., Liu, X., Butler, B.R., Froelich, C.J. and Thor, A.D. (2001) Reconstitution of Caspase 3 Sensitizes MCF-7 Breast Cancer Cells to Doxorubicin-and Etoposide-Induced Apoptosis. Cancer Research, 61, 348-354.

[19] Teitz, T., Wei, T., Valentine, M.B., Vanin, E.F., Grenet, J., Valentine, V.A. and Kidd, V.J. (2000) Caspase 8 Is Deleted or Silenced Preferentially in Childhood Neuroblastomas with Amplification of MYCN. Nature Medicine, 6, 529-535. https://doi.org/10.1038/75007

[20] Shivapurkar, N., Toyooka, S., Eby, M.T., Huang, C.X., Sathyanarayana, U.G., Cunningham, H.T. and Chaudhary, P.M. (2013) Differential Inactivation of Cas- 
pase-8 in Lung Cancers. Cancer Biology and Therapy, 14, 1074. https://doi.org/10.4161/cbt.26923

[21] Soengas, M.S., Alarcon, R.M., Yoshida, H., Hakem, R., Mak, T.W. and Lowe, S.W. (1999) Apaf-1 and Caspase-9 in p53-Dependent Apoptosis and Tumor Inhibition. Science, 284, 156-159. https://doi.org/10.1126/science.284.5411.156

[22] Champion, C., Guianvarc'h, D., Sénamaud-Beaufort, C., Jurkowska, R.Z., Jeltsch, A., Ponger, L. and Guieysse-Peugeot, A.L. (2010) Mechanistic Insights on the İnhibition of c5 DNA Methyltransferases by Zebularine. PloS ONE, 5, e12388. https://doi.org/10.1371/journal.pone.0012388

[23] Yoo, C.B., Cheng, J.C. and Jones, P.A. (2004) Zebularine: A New Drug for Epigenetic Therapy.

[24] Pompeia, C., Hodge, D.R., Plass, C., Wu, Y.Z., Marquez, V.E., Kelley, J.A. and Farrar, W.L. (2004) Microarray Analysis of Epigenetic Silencing of Gene Expression in the KAS-6/1 Multiple Myeloma Cell Line. Cancer Research, 64, 3465-3473. https://doi.org/10.1158/0008-5472.CAN-03-3970

[25] Napso, T. and Fares, F. (2014) Zebularine İnduces Prolonged Apoptosis Effects via the Caspase-3/PARP Pathway in Head and Neck Cancer Cells. International Journal of Oncology, 44, 1971-1979. https://doi.org/10.3892/ijo.2014.2386

[26] Candiloro, I.L., Mikeska, T., Hokland, P. and Dobrovic, A. (2008) Rapid Analysis of Heterogeneously Methylated DNA Using Digital Methylation-Sensitive High Resolution Melting: Application to the CDKN2B (p15) Gene. Epigenetics \& Chromatin, 1, 7. https://doi.org/10.1186/1756-8935-1-7

[27] Martens, J.W., Margossian, A.L., Schmitt, M., Foekens, J. and Harbeck, N. (2009) DNA Methylation as a Biomarker in Breast Cancer. Future Oncology, 5, 1245-1256. https://doi.org/10.2217/fon.09.89

[28] Bradbury, J. (2004) Zebularine: A Candidate for Epigenetic Cancer Therapy. Drug Discovery Today, 9, 906-907. https://doi.org/10.1016/S1359-6446(04)03266-0

[29] Cheng, J.C., Yoo, C.B., Weisenberger, D.J., Chuang, J., Wozniak, C., Liang, G. and Jones, P.A. (2004) Preferential Response of Cancer Cells to Zebularine. Cancer Cell, 6, 151-158. https://doi.org/10.1016/j.ccr.2004.06.023

[30] Yang, P.M., Lin, Y.T., Shun, C.T., Lin, S.H., Wei, T.T., Chuang, S.H. and Chen, C.C. (2013) Zebularine Inhibits Tumorigenesis and Stemness of Colorectal Cancer via p53-Dependent Endoplasmic Reticulum Stress. Scientific Reports, 3, 3219. https://doi.org/10.1038/srep03219

[31] Ruiz-Magaña, M.J., Rodríguez-Vargas, J.M., Morales, J.C., Saldivia, M.A., SchulzeOsthoff, K. and Ruiz-Ruiz, C. (2012) The DNA Methyltransferase Inhibitors Zebularine and Decitabine Induce Mitochondria-Mediated Apoptosis and DNA Damage in p53 Mutant Leukemic T Cells. International Journal of Cancer, 130, 1195-1207. https://doi.org/10.1002/ijc.26107

[32] Nakamura, K., Nakabayashi, K., Aung, K.H., Aizawa, K., Hori, N., Yamauchi, J. and Tanoue, A. (2015) DNA Methyltransferase İnhibitor Zebularine Induces Human Cholangiocarcinoma Cell Death through Alteration of DNA Methylation Status. PloS ONE, 10, e0120545. https://doi.org/10.1371/journal.pone.0120545

[33] Tan, W., Zhou, W., Yu, H.G., Luo, H.S. and Shen, L. (2013) The DNA Methyltransferase Inhibitor Zebularine Induces Mitochondria-Mediated Apoptosis in Gastric Cancer Cells in Vitro and in Vivo. Biochemical and Biophysical Research Communications, 430, 250-255. https://doi.org/10.1016/j.bbrc.2012.10.143

[34] Balch, C., Yan, P., Craft, T., Young, S., Skalnik, D.G., Huang, T.H. and Nephew, K.P. (2005) Antimitogenic and Chemosensitizing Effects of the Methylation Inhibitor 
Zebularine in Ovarian Cancer. Molecular Cancer Therapeutics, 4, 1505-1514. https://doi.org/10.1158/1535-7163.MCT-05-0216

[35] Yamaguchi, H., Wyckoff, J. and Condeelis, J. (2005) Cell Migration in Tumors. Current Opinion in Cell Biology, 17, 559-564.

https://doi.org/10.1016/j.ceb.2005.08.002

[36] Hellebrekers, D.M., Jair, K.W., Viré, E., Eguchi, S., Hoebers, N.T., Fraga, M.F. and Griffioen, A.W. (2006) Angiostatic Activity of DNA Methyltransferase Inhibitors. Molecular Cancer Therapeutics, 5, 467-475. https://doi.org/10.1158/1535-7163.MCT-05-0417

[37] Zhou, P., Lu, Y. and Sun, X.H. (2012) Effects of a Novel DNA Methyltransferase Inhibitor Zebularine on Human Lens Epithelial Cells. Molecular Vision, 18, 22.

[38] Salvesen, G.S. and Riedl, S.J. (2008) Caspase Mechanisms. In: White, R.K.-F., Ed., Programmed Cell Death in Cancer Progression and Therapy, Springer, Dordrecht, 13-23. https://doi.org/10.1007/978-1-4020-6554-5_2

[39] Parrish, A.B., Freel, C.D. and Kornbluth, S. (2013) Cellular Mechanisms Controlling Caspase Activation and Function. Cold Spring Harbor Perspectives in Biology, 5, a008672. https://doi.org/10.1101/cshperspect.a008672

[40] Nakamura, K., Aizawa, K., Nakabayashi, K., Kato, N., Yamauchi, J., Hata, K. and Tanoue, A. (2013) DNA Methyltransferase Inhibitor Zebularine Inhibits Human Hepatic Carcinoma Cells Proliferation and Induces Apoptosis. PloS ONE, 8, e54036. https://doi.org/10.1371/journal.pone.0054036

[41] Eroglu, O., Baysak, M.E., Aras, B.D., Cilingir, O. and Artan, S. (2018) Detection of Promoter Hypermethylation of GSTP1 and CDH1 Genes and the Relationship of Histopathological Parameters of the Breast. Advances in Breast Cancer Research, 7, 91-106. https://doi.org/10.4236/abcr.2018.72006 